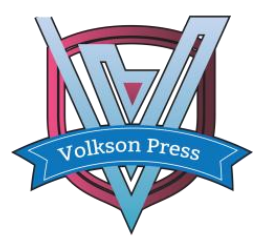

Contents List available at VOLKSON PRESS

Mechanical and Control Engineering (MCE)

DOI : http://doi.org/10.26480/wsmce.01.2017.105.107

\title{
THE INNOVATIVE DESIGNING OF THE CONNECTING-ROD SWINGROD GEAR- DRIVING INTERNAL-COMBUSTION ENGINES
}

\author{
Yi Fan \\ Transportation College, Nanning University, Nanning City Guangxi Province, China \\ *Corresponding Author Email: 64608769@qq.com
}

This is an open access article distributed under the Creative Commons Attribution License, which permits unrestricted use, distribution, and reproduction in any medium, provided the original work is properly cited

\section{ARTICLE DETAILS}

\section{Article History:}

Received 02 october 2017

Accepted 06 october 2017

Available online 11 november 2017

Keywords

gear driving, connecting-rod and swing-rod, internal-combustion engine, shaft torsion

\section{ABSTRACT}

Aiming at the current problems like short drive arms and low mechanism efficiency existed in the crank connecting rod piston internal-combustion engines, the paper proposes a design of a kind of connecting-rod swing-rod geardriving internal-combustion engine that can convert two reversal thrusts of the piston linear reciprocating motion into two reversal torques of the swing rod and then into one one-way torque by the gear sets. The maximum piston thrust $\mathrm{F}$ are highly converted into the shaft torsion Ft, which makes the connecting-rod swing-rod gear-driving internal-combustion engines' maximum shaft torque increase by about 34\% than that of the crank engines. What's more, the effective fuel consumption rate is reduced. The connecting-rod swing-rod gear-driving internalcombustion engines directly use the mature technology of the traditional internal-combustion engines' straight reciprocating piston structure to trial-manufacture the prototypes and produce in enormous quantities. Production difficulty will be less than ever. The internal-combustion engines' environmental performance is improved.

\section{Introduction}

Nowadays, the internal-combustion engines are widely used in some important areas like industry and agriculture, communications and transportation industry and national defense industry. Due to the world's greatly increasing demand, both the social benefit and the economic benefit of the internal-combustion engines are notable. Some developed countries even consider the industries that take the internal-combustion engines as the core as the most important economic base. Big cities are crowded with automobiles; people suffer from the serious pollution from the internal-combustion engines. Under these background, every country constantly makes stricter and stricter demands and restrictions to the internal-combustion engines, eliminates the backwards, and finally popularizes the environmental protective. Therefore, developing goodperformance internal-combustion engines can bring good social benefit and economic benefit. They will have a bright market prospects.

The current cylinder-piston internal-combustion engines use the crankshaft connecting rod and slider conversion mechanism. It is known that the crankshaft connecting rod and slider conversion mechanism has a 0 point, and its theoretical mechanical efficiency is $2 / \pi$. Its piston stroke approximately equals to the cylinder diameter, which cannot be lengthened at will. The exhaust gas pressure is around $0.105 \mathrm{Mpa}$ to $0.12 \mathrm{Mpa}$. The temperature is between $427^{\circ} \mathrm{C}$ and $627^{\circ} \mathrm{C}$. The piston stroke cannot be lengthening either. Although the turbine converts some exhaust gas pressure into the inlet pressure and improves the power of the internal-combustion engine, the effective thermal efficiency of the practical internal-combustion engine still hovers around $40 \%$, and it is hard to go beyond $50 \%$. The maximum thermal efficiency of the laboratory diesel engines can only reach $52 \%$.

For over a century, people have put the rotor and the eccentric gear as the research direction, thinking the mechanical efficiency may be high by reducing the intermediate links. Felix Wankel in Germany developed the rotary engine and solved the sealing problem in 1957. However, the eccentric gear transmission had two fatal smalls. One was the gas expansion coefficient (the Maximum volume ratio and the minimum volume ratio of gas) small, the other was the arm of force small [1-2]. When the rotary engine decelerates, these two smalls produce backfire and much $\mathrm{CH}$ with a high exhaust temperature, a high effective fuel consumption rate and a bad low-speed performance. What's more, its effective thermal efficiency and the environmental compatibility is lower than that of the crank connecting rod reciprocating piston internal-combustion engine (Crank Engine for short), which has no economic and practical significance. Today, the four-stroke crank machine is widely used for its technological maturity.

\section{THE INNOVATIVE DESIGNING OF THE CONNECTING-ROD SWING- ROD GEAR-DRIVING INTERNAL-COMBUSTION ENGINES}

According to the fundamental law of gearing, the ideal mechanical efficiency of gear driving is $100 \%$, and the gear ratio can equal to the effect of the force transformation. For example, see [3]. From the Line $p-\varphi$ of the four-stroke crank machine in Figure 3, the tangential force of the crankshaft is Ft. The crankshaft radius of gyration is $r$. The crank rotation angle is $\varphi$, and the swing angle of connecting $\operatorname{rod}$ is $\beta$. $F t=F \sin (\varphi+\beta) / \cos \beta$. Suppose the connecting rod length $L$ equal to three $r$, and we can draw the crankshaft torque Line $\mathrm{Ft}$ of the four-stroke crank machine as the Line (2) Ft- $\varphi$ in Figure 3. From Line Ft- $\varphi$ in Figure 3, when it is 0 degree or 180 degrees, the value of $\mathrm{Ft}$ is 0 , and there is a peak value between these two points. The peak value of $\mathrm{Ft}$ is at about 25 degrees to 65 degrees in $\varphi$. Ft=F $\sin (\varphi+\beta) / \cos \beta$. The peak value of line Ft is influenced by the peak value of Line (1) F- $\varphi$. Its peak value removes ahead to 0 degree to 25 degrees of $\varphi$.

In Figure 3, the peak value of Line $\mathrm{F}$ is between 0 and $25^{\circ}$, while Line $\mathrm{F}_{\mathrm{t}}$ 's is between $25^{\circ}$ and $65^{\circ}$. These two miss each other. The maximum $\mathrm{F}$ value of Line $\mathrm{F}_{\mathrm{t}}-\varphi$ is only about half of Line F- $\varphi$ 's.

The gear driving can effectively change the peak value $\mathrm{F}$ of the early thrust from the gas to the piston into the shaft torsion $F_{t}$. At the same time, the piston stroke of the gear driving can be arbitrarily chosen, and the ratio of the piston stroke and the cylinder diameter can be increased. What's more, the exhaust temperature and pressure are close to the outside air and the exhaust gas pressure is working. So, the effective thermal efficiency is enhanced, and the environmental compatibility is improved. Here comes the problem that there may be damaged collision, jamming and interference when using the gear to shift two reversal torques into one one-way torque [4]. This paper proposes a kind of connecting-rod swingrod Gear-driving Internal-combustion Engine which can help to realize the following three aspects. Firstly, two reversal thrusts of the piston linear reciprocating motion are converted into two reversal torques of the swing rod. Secondly, these two reversal torques of the swing rod are converted into one one-way torque by the gear sets. Thirdly, conditions are created 
to make the gear sets work normally. Then, all the above problems are solved. Especially when the gear driving can go straight through the piston internal-combustion engine, the Crank Engine's mature technology can directly be used in cylinders, pistons, sealing, gas distribution, oil supply, lubrication and so on. Production difficulty will be less than ever.

\section{STRUCTURE DESIGN AND ANALYSIS}

The structure design of the two-cylinder four-stroke connecting-rod swing-rod gear-driving internal-combustion Engines (Four-stroke Swingrod Gear-driving Engines for short):

3.1 Measures of Converting two reversal thrusts of the piston linear reciprocating motion $F$ and $-F$ into two reversal torques of the swing rod FR and - FR

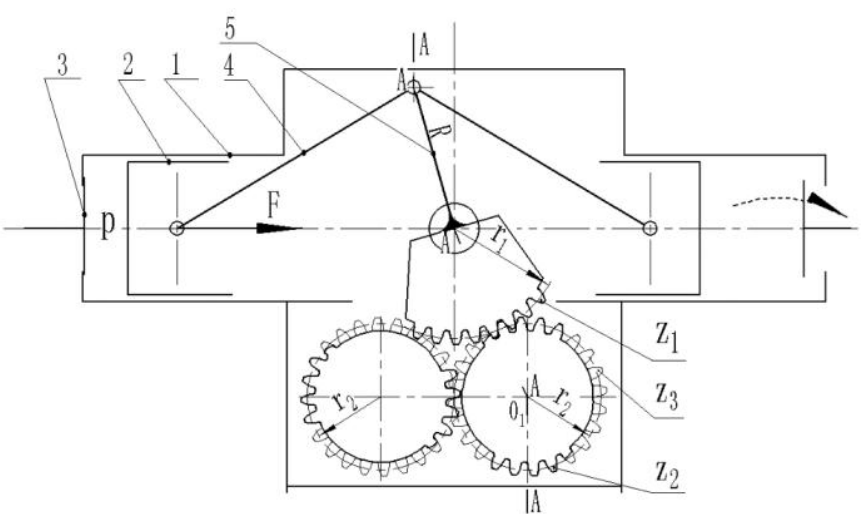

Figure 1: Section Figure of the Four-stroke Connecting-rod Swing-rod Gear Driving Going Through the Internal-combustion Engine

In Figure 1, one side of the two rods 4 is hinged together with Piston 2, while the other side of the two rods is hinged together with Swing Rod 5. At the same time, two cylinders are set oppositely. Gas in the cylinders expands, and pushes forward the piston to generate thrust F. The piston pushes Connecting Rod 4 to generate thrust F1. Then, the connecting rod pushes Swing Rod 5 to produce torsion FR, while the reversal pistons produce torsion -FR for the swing rod. The torques can be calculated like this: $T R=R F R,-T R=-R F R$

\subsection{Measures of Using the Gear Sets to Converting Two Reversal Torques of the Swing Rod into One One-way Torque}

The swing rod is coaxial with the incomplete gear $Z_{1} . Z_{1}$ has two reversal torsions $\left(F_{r 1}=F_{R} R / r_{1},-F_{r 1}=-F_{R} R / r_{1}\right)$ and two reversal torques $\left(T_{r 1}=R F_{R}\right.$, $\left.T_{r 1}=-R F_{R}\right) . Z_{1}$ is the driving gear in the gear sets. When $Z_{1}$ swings, two reversal torsions $\left(\mathrm{F}_{\mathrm{r} 1},-\mathrm{F}_{\mathrm{r} 1}\right)$ and two reversal torques $\left(\mathrm{T}_{\mathrm{r} 1},-\mathrm{T}_{\mathrm{r} 1}\right)$ are transmitted to two reversely rotating incomplete gears $\mathrm{Z}_{2}$. $\mathrm{Z}_{2}$ has two reversal torsions $\left(\mathrm{F}_{\mathrm{r} 2},-\mathrm{F}_{\mathrm{r} 2}\right)$ and two reversal torques $\left(\mathrm{T}_{\mathrm{r} 2}=\mathrm{r}_{2} \mathrm{~F}_{\mathrm{r} 2}=R \mathrm{R}_{\mathrm{R}}\left(\mathrm{r}_{2} / \mathrm{r}_{1}\right)\right.$, $\left.-\mathrm{T}_{\mathrm{r} 2}=-\mathrm{r}_{2} \mathrm{~F}_{\mathrm{r} 2}=-\mathrm{RF}_{\mathrm{R}}\left(\mathrm{r}_{2} / \mathrm{r}_{1}\right)\right)$. Two $\mathrm{Z}_{2}$ are coaxial with two gear $\mathrm{Z}_{3}$ whose pitch radius is $r_{3}$. Two $Z_{3}$ mesh smoothly. And two reversal torsions and two reversal torques of $\mathrm{Z}_{2}$ convert into an arbitrary one-way torsion $\mathrm{F}_{\mathrm{r} 2}$ of the Axis $Z_{2}$ and a one-way torque $\mathrm{RF}_{\mathrm{R}}\left(\mathrm{r}_{2} / \mathrm{r}_{1}\right)$.

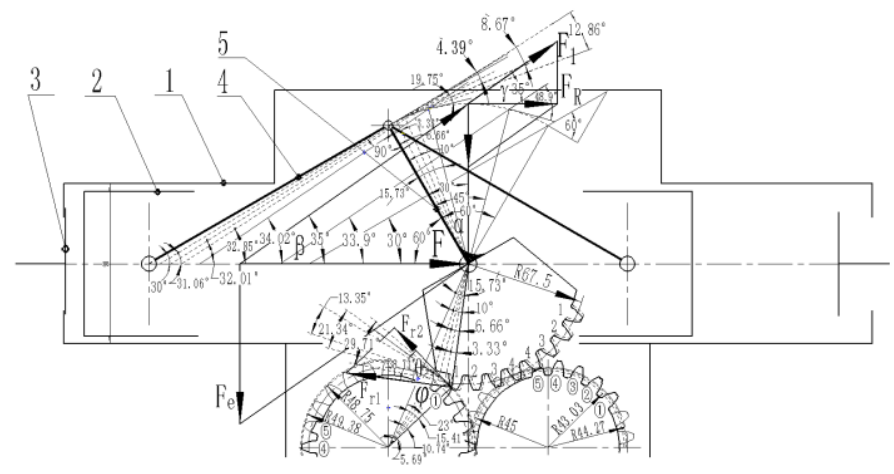

Figure 2: Figure of Converting the Piston Thrust F of the Four-stroke Connecting-rod Swing-rod Gear Driving Going Through the Internalcombustion Engines into the Shaft Torsion $\mathrm{F}_{\mathrm{r} 2}$

In Figure 2 , there is an angle $\beta$ in the axis connection between the connecting rods and the piston hinge. $\beta$ Corresponds with the angle $\gamma$ between the connecting-rod force $F_{1}$ and the swing-rod normal force $F_{R}$. $F_{R}=F \cos \gamma / \cos \beta$. From Figure 2, it can be seen that within the first $15.73^{\circ}$ of the swing-rod, the meshing point of $Z_{1}$ 's gear 1 and the $Z_{2}$ 's gear 1 is not on the two-gear-linking line, and $\mathrm{Z}_{1}$ 's torsion $\mathrm{F}_{\mathrm{r} 1}$ and $\mathrm{Z}_{2}$ 's torsion $\mathrm{F}_{\mathrm{r} 2}$ form an angle $\theta$. Therefore, $\mathrm{F}_{\mathrm{r} 2}=\mathrm{RF}_{\mathrm{R}}\left(\mathrm{r}_{2} / \mathrm{r}_{1}\right) \cos \theta=\mathrm{RF}\left(\mathrm{r}_{2} / \mathrm{r}_{1}\right) \cos \beta \cos \theta / \cos \gamma$. Let's suppose that the cylinder's diameter $\mathrm{d}$ is $90 \mathrm{~mm}$, the radius $\mathrm{r} 45 \mathrm{~mm}$. Then $\mathrm{Z}_{2}$ 's tangential force $\mathrm{F}_{\mathrm{t}}$ is equal to $\mathrm{F}_{\mathrm{r} 2}$. The length of the swing rod $\mathrm{R}$ is $90 \mathrm{~mm}$, which is two times of $\mathrm{r}$. $\mathrm{r}_{1}$ is $67.5 \mathrm{~mm}$, which is one and a half times of $r_{1} r_{2}$ is $45 \mathrm{~mm}$, which is equal to $r$. Take any $Z_{2}$ as the shaft, and its torque can be calculated: $\mathrm{T}_{\mathrm{r} 2}=\mathrm{r}_{2} \mathrm{~F}_{\mathrm{r} 2}=\mathrm{rF}_{\mathrm{t}}=\quad \mathrm{RF}\left(\mathrm{r}_{2} / \mathrm{r}_{1}\right) \cos \gamma \cdot \cos \theta / \operatorname{co} \quad \mathrm{s} \beta=4 \mathrm{rF}$ $\cos \gamma \cdot \cos \theta / 3 \cos \beta$. When the swing rod swing 60 degrees, $\mathrm{Z}_{2}$ turns 90 degrees. In Figure 2 , the values of Z $Z_{2}^{\prime}$ s angle $\varphi$ and the swing rods angle $\gamma$, $\theta, \beta$ are used in the formula to calculate the shaft torsion $F_{t}$ when its piston stroke is $1 \mathrm{~d}$, and the shaft turns 180 degrees. $\mathrm{F}_{\mathrm{t}}=4 \mathrm{~F} \cos \gamma \cdot \cos \theta / 6 \cos \beta$. The shaft torsion when its piston stroke is $1 \mathrm{~d}$, and the shaft turns 90 degrees can also be calculated. $\mathrm{F}_{\mathrm{t}}=4 \mathrm{~F} \cos \gamma \cdot \cos \theta / 3 \cos \beta$.

In Line F- $\varphi$ of the Four-stoke Crank Engine, the piston stroke is $1 \mathrm{~d}$ and the shaft turns 180 degrees, while the Four-stoke Swing-rod Gear-driving Engine's piston stroke is $1 \mathrm{~d}$ and its shaft turns 90 degrees. Therefore, $\delta$ can be used in Line to present Value $\mathrm{F}$ and Value $\mathrm{F}_{\mathrm{t}} \mathrm{F}_{\mathrm{t}}=4 \mathrm{~F} \cos \gamma \cdot \cos \theta / 3 \cos \beta . \mathrm{F}_{\mathrm{t}}$ matches with the Value $\mathrm{F}$ of $2 \varphi$. Put the Value $\mathrm{F}_{\mathrm{t}}(\mathrm{Ft}=4 \mathrm{~F} \cos \gamma \cdot \cos \theta / 3 \cos \beta)$ when $2 \varphi$ 's piston stroke is $1 \mathrm{~d}$ and its shaft turns 90 degrees into $\varphi$ in Figure 3 , we can get Line (3) $11 \mathrm{~d} 90^{\circ} \mathrm{Ft}-\varphi[\mathrm{Ft}=4 \mathrm{~F} \cos \gamma \cdot \cos \theta / 3 \cos \beta]$. Put the Value $\mathrm{F}_{\mathrm{t}}\left(\mathrm{F}_{\mathrm{t}}=4 \mathrm{~F} \cos \gamma \cdot \cos \theta / 6 \cos \beta\right)$ when $\varphi$ 's piston stroke is $1 \mathrm{~d}$ and its shaft turns 180 degrees into $\varphi$ in Figure 3, we can get Line (4). $1 \mathrm{~d} 180^{\circ} \mathrm{F}_{\mathrm{t}}-\varphi$ $[\mathrm{Ft}=4 \mathrm{~F} \cos \gamma \cdot \cos \theta / 6 \cos \beta]$.

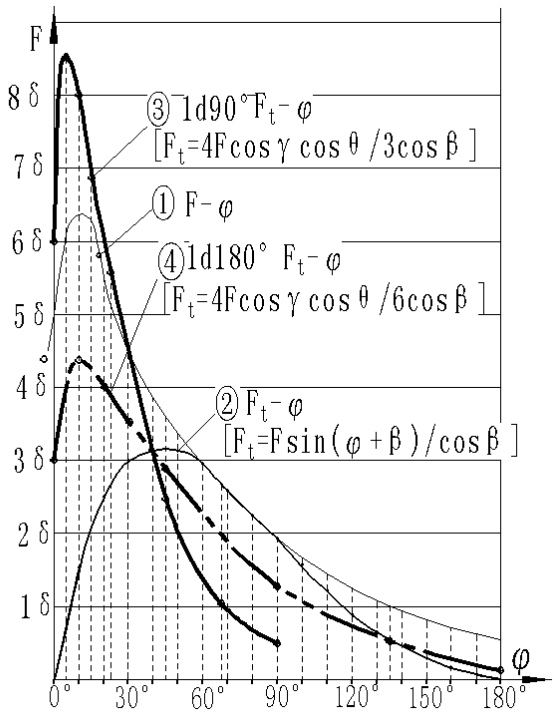

Figure 3: Comparison Figure of the Four-stroke Connecting-rod Swing-rod Gear driving Going Through the Internal-combustion Engine's Line $\mathrm{F}_{\mathrm{t}}-\varphi$ and the Crank Engine's Line $\mathrm{F}_{\mathrm{t}}-\varphi$

In Figure 3, it can be intuitively seen that the shaft output torque of the Four-stroke Swing-rod Gear-driving Engine is bigger than that of the Fourstroke Crank Engine. When the piston stroke is $1 \mathrm{~d}$ and the shaft turns 90 degrees, the maximum shaft output torque of the Four-stroke Swing-rod Gear-driving Engine is 2.6 times as much as that of the Four-stroke Crank Engine. When the piston stroke is $1 \mathrm{~d}$ and the shaft turns 180 degrees, the maximum shaft output torque of the Four-stroke Swing-rod Gear-driving Engine is 1.34 times as much as that of the Four-stroke Crank Engine. That means it increases by about $34 \%$.

\subsection{Creating Conditions to Make the Gear Sets Work Normally}

When gears drive, conditions should be created to make the gear sets work normally in order to avoid the gears' jamming, interference and damaged collision and to achieve the presupposed results of the gears driving Accordingly, the following gears selection and profile modification should be made [5]:

Select the pitch radius of the gear according to the transmission ratio as in Figure 1 and Figure 2: the swing rod swing 60 degrees and the shaft $\mathrm{Z}_{2}$ turns 90 degrees. The transmission ratio is $i_{12}$. $i_{12}=\omega 1 / \omega 2=60^{\circ} / 90^{\circ}=2 / 3$. The radius $r_{1}$ of $z_{1}$ is $67.5 \mathrm{~mm}$. The radius $r_{2}$ of $z_{2}$ is $45 \mathrm{~mm} .45 / 67.5=2 / 3$.

Remove the no-driving-function gears between the driving gear $\mathrm{z}_{1}$ and the driven gear $\mathrm{z}_{2}$, which makes $\mathrm{z}_{1}$ and $\mathrm{z}_{2}$ become imperfect gears and eliminates the possibility of driving's jamming and interference.

Set up the meshing gear's anti-jamming clearance $\mathrm{S}$ greater than or equal 
to 0 as in Figure 2. $S=49.38 \mathrm{~mm}-48.75 \mathrm{~mm}=0.63 \mathrm{~mm}$.

Modify the tooth height of the engaging-out gear, and produce an antijamming clearance $\mathrm{S}$ for the meshing gear. As in Figure 2, the distance from the addendum of Tooth (5) to its gear center is R44.27, and we can get the value $\mathrm{S} 0.65 \mathrm{~mm}$.

Modify the slope of the engaging-out gear, and make it slowly close to the meshing gear. As in Figure 2, one third of the addendum of Tooth (5) is flat, while the other parts are slope. The slope intersets with the profile that is R43.03, which makes the meshing gear slides on the slope and makes the engaging-out gear slowly get in touch.

\subsection{Cylinder blocks in parallel}

Several cylinder blocks should be connected in parallel to work in order to get higher power. The Four-stroke Swing-rod Gear-driving Engine listed here makes two cylinders into one-cylinder block. If all the cylinders are placed in parallel together, one cylinder is one-cylinder block. Several cylinder blocks are connected in parallel to work.

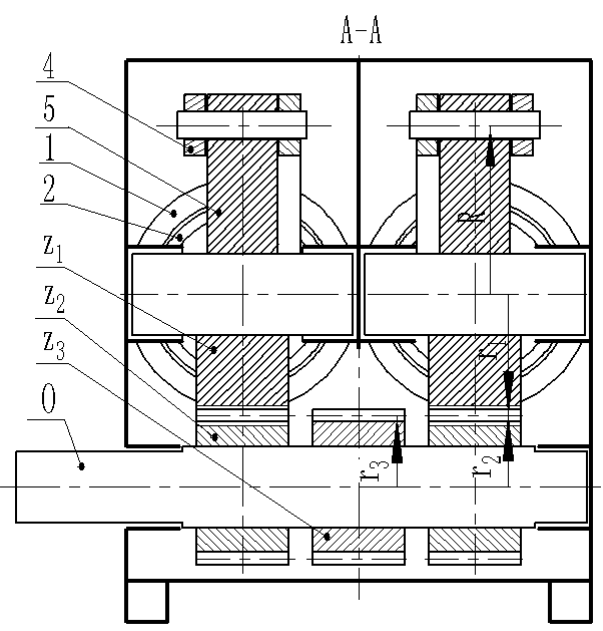

Figure 4: A-A Profile Figure of Two Cylinder Blocks Cooperating

As in Figure 4, two-cylinder blocks are placed in parallel sharing two gears to form a two-cylinder four-stroke swing-rod gear-driving engine. One piston works to drive one stroke, and four cylinders drive four strokes. Two cylinders are connected in parallel, while one piston works in every stroke. Internal-combustion engine's shafts can continuously output the torque. Using this method, several cylinder blocks are in parallel and can work cooperatively. Increasing the piston stroke and fully using the tail gas to drive the piston to work can greatly improve the effective thermal efficiency.

\section{CONCLUSION}

The connecting-rod swing-rod gear-driving internal-combustion engines directly use the mature technology of the traditional internal-combustion engines' straight reciprocating piston structure to trial-manufacture the prototypes and produce in enormous quantities. Production difficulty will be less than ever.

The maximum piston thrust $\mathrm{F}$ are highly converted into the shaft torsion $\mathrm{Ft}$, which makes the connecting-rod swing-rod gear-driving internalcombustion engines' maximum shaft torque increase by about $34 \%$ than that of the crank engines. What's more, the effective fuel consumption rate is reduced.

The tail gas is effectively utilized to do useful work, and the effective thermal efficiency of the connecting-rod swing-rod gear-driving internalcombustion engines is heightened. At the same time, the exhaust gas temperature and pressure are diminished, and the noise pollution and thermal pollution are greatly reduced. The internal-combustion engines' environmental performance is improved.

\section{ACKNOWLEDGMENTS}

This paper was financially supported by the Basic Ability Promotion Project of Young and Middle-aged Teachers in Guangxi Universities (2017KY1437) and the Professor Foster Project of Nanning University (2016JSGC07).

\section{REFERENCES}

[1] Antonelli, M., Baccioli, A., Francesconi, M., Desideri, U., Martorano, L. 2014. Operating maps of a rotary engine used as an expander for microgeneration with various working fluids. Applied Energy, 113 (2), 742-750.

[2] Fan, B., Pan, J., Yang, W., Zhu, Y., Chen, W. 2016. Effects of hydrogen blending mode on combustion process of a rotary engine fueled with natural gas/hydrogen blends. International Journal of Hydrogen Energy, 41 (6), 4039-4053.

[3] Zhou, L., Liu, Y., Gao, Z. 2005. Internal combustion engine. Beijing, China Machine Press.

[4] Fernández, A., Iglesias, M., DeJuan, A., García, P., Sancibrián, R. Viadero, F. 2014. Gear transmission dynamic: Effects of tooth profile deviations and support flexibility. Applied Acoustics, 77 (2), 138-149.

[5] Chen, B., Liang, D., Gao, Y. 2014. Geometry design and mathematical model of a new kind of gear transmission with circular arc tooth profiles based on curve contact analysis. Proceedings of the Institution of Mechanical Engineers, Part C: Journal of Mechanical Engineering Science, 228 (17), 3200-3208. 